\title{
A Descriptive Study to Assess the Problem Faced by the Adolecents of Alcoholic Parent
}

\author{
Saranbharati.B ${ }^{1}$, Ramya. ${ }^{1}$, Rajalakshmi ${ }^{1}$, Devaki. $K^{2}$ \\ ${ }^{1}$ B.Sc (NURSING) Student, Chettinad College of Nursing, M.Sc (Nursing), M.sc (Psychology), Nursing Tutor, \\ Chettinad College of Nursing,Chettinad Academy of Research and Education, Tamilnadu
}

\begin{abstract}
A descriptive study to assess problems faced by the adolescents of alcoholic parent in selected community area, Kancheepuram district, Tamil Nadu. Objectives of the study to assess the problems faced by the adolescents of alcoholic parents and to find out association between the problems faced by the adolescents of alcoholic parent with their selected demographic variables. Non experimental approach and descriptive design used for this study. Samples were selected by using purposive sampling technique. The sample consisted of 50 adolescents. Self-structured questionnaires for assessment of demographic variables and used to assess the problem faced by adolescents of alcoholic parents. The data collected from 50 adolescents (Grils and boys) in the age group between 15 to 18 years. Study show that 9(18\%) severe problems, 31(62\%) moderate problems and 10(20\%) mild problems. Study shows that there was significant association between the levels of problem faced by the adolescents of alcoholic parent with age and occupation of alcoholic parent ( $\mathrm{p}$ value $=<0.05)$.
\end{abstract}

Key words: assess, problems, alcoholic parent, adolescents.

\section{Introduction}

Alcoholism today clearly seen as a family disease ravaging not just the individual who drinks excessively but also the entire family. The primary victim is the individual who drinks excessively, no doubt, but the family members are also affected with just the same intensity, if not more. Families complicated by alcoholism can be considered as families in a never ending series of crisis. Alcoholism disrupts even normal routine family tasks and function, increase conflicts and demands adaptive responses from family members who simply do not know 'how' to respond appropriately. The social stigma associated with alcoholism, the economic drain on the family's resources, the threat to physical well-being job insecurity all compound to the problem ${ }^{[4]}$

An estimated 6.6 million children under the age of 18yrs live in household with at least one alcoholic parent. Current research findings suggest that these children are at a risk for a range of cognitive, emotional and behavioural problems. ${ }^{[1]}$ Between 15 and 20 per cent of Indian people consume alcohol and, over the past twenty years, the number of drinkers has increased from one in 300 to one in 20. In globally today in there are an estimated 28 million children who have alcoholic parents. The adolescents world wide 10 to 24 years is 356 million, ${ }^{[3]}$ Tamil Nadu 1.24 crore, India 253 million. According to 2012 in India report approximately 1.28 Million Parents have a alcohol addiction problem.11 million of those children under the age of 18. In 2012 about 3.3 million death or $5.9 \%$ of all global death due to alcohol consumption. ${ }^{[3]}$

\section{Method}

Adolescents (Girls and Boys) who were in the selected community area (pooncheri \& payanoor) in the age group between 15 to 18 years residing in a selected community area, Kanchipuram district, Tamil Nadu, 50 samples were choosen for the present study.

\section{Design}

In this study non experimental research approach and Descriptive research design adopted, Purposive sampling technique adopted. Self-structured questionnaires consist of 20 questions used and self -structured questionnaires to assess demographic variables. Each sample will take 30 minute to completion of the data. 


\section{Instrument/material}

Self-structured questionnaires consist of 20 questions used and self -structured questionnaires to assess demographic variables. Each sample will take 30 minute to completion of the data. There are Two Section (A\&B) Section A consist of self-Structured Questionnaires to assess demographic variable \& Section B Self-Structured Questionnaires to assess the problem faced by the adolescents of alcoholic parent consist of 20 questions.

\begin{tabular}{|l|l|}
\hline \multicolumn{2}{|l|}{ SCORING INTERPRETATION } \\
\hline SCORING & INTERPRETATION \\
\hline $\mathbf{2 7 - 4 0}$ & Severe \\
\hline $\mathbf{2 6 - 1 4}$ & Moderate \\
\hline $\mathbf{1 3 - 1}$ & Mild \\
\hline
\end{tabular}

Procedure

The written informed consent was obtained from the parent and guardian as well as from the study participants. Permission letter was obtained from the HOD of Mental Health Nursing department, HOD of Community Health Nursing department, Community area, UG Committee and Human Ethical Committee.

\section{Statistical Analysis}

Descriptive statistics like frequency distribution, percentage, mean, standard deviation and inferential statistics like chi square was used to analyse the data.

\section{Result:}

The study finding revealed that,

* Our study results shows that assessing the levels of problems faced by the adolescent of alcoholic parent $31(62 \%)$ moderate problems, $10(20 \%)$ mild problem and $9(18 \%)$ severe problem.

Table 1 Frequency and percentage distribution of problems faced by the adolescents of alcoholic parents.

\begin{tabular}{|l|l|l|l|}
\hline S.no & Problems Level & Frequency & $\begin{array}{l}\text { Percen- } \\
\text { Tage }\end{array}$ \\
\hline 1. & Mild problems & 10 & $20 \%$ \\
\hline 2. & Moderate problems & 31 & $62 \%$ \\
\hline 3. & Severe problems & 9 & $18 \%$ \\
\hline
\end{tabular}

$(\mathbf{N}=\mathbf{5 0})$

\section{Discussion}

The study was conducted to assess $\mathrm{H} 1$ there is a significant association between the levels of problems faced by the adolescents of alcoholic parent with selected demographic variable and to assess $\mathrm{H}_{2}$ There is significant association between the problems faced by the alcoholic parent and selected Demographic data. The hypothesis $\mathrm{H}_{1}$ and $\mathrm{H}_{2}$ was accepted suggestion that there will be significant association between the level of problems faced by the adolescents of alcoholic parent and the selected demographic characteristics of adolescents. The finding revealed that the problems has statistically significant with age of adolescent and occupation of alcoholic parent $p$ value $<0.05$ level and other variables are not significant. The limitation of the study was the data collection period was limited for one week. Large number of sample could not be obtained due to difficulty found the samples in the age group of 15 to 18 years of adolescent of alcoholic parent for data collection. Based on the findings of the study, following recommendation are put forth the study can be done on a large sample thereby findings can be generalized. a similar study can be conducted using teaching strategies like structured teaching programme, video assisted teaching. The nurse researcher will help us to know the adolescents with severe problems and give them awareness and psychological support and helpline numbers to prevent or to reduce the problem. On the basis of conducted research it can be concluded the assessment of problem faced adolescent by the adolescent of alcoholic parent has a important determination of early prevention from complication. Problems faced by adolescent of alcoholic parent and associated factor in previous study shows that the study to assess the problem faced by the adolescents of alcoholic father. The study is consisted of 60 adolescents . Study finding data shows that most $(61.66 \%)$ of the children were females and $38.3 \%$ were males. The data presented was shows no association between physical health status and selected demographic variables like sex, age, duration of father's alcoholism, treatment received for alcoholism except to income of family per months at significance of 0.05 level. Deepa shaji Thomas et al (2012).

Ethical Clearance: Chettinad Academy of Research \& Education - Institution Human Ethics Committee.

\section{Source of Funding: Self}

Confilct of Interest: Nil 


\section{References}

1. Ms.Revathy. G.S.A Study to assess the self- esteem of adolescents whose parents are alcoholics. Bengaluru. (2010).

2. U.Nagarani. A Descriptive study to assess the problems faced by wife of alcoholic dependents. Dindigul.(2015).

3. Olga wlodarczyk, Mirjamschwarze, Hansjurgenrumpf, Frankametzner, Silkepavils. A Study to assess the productive mental health factor in children of parents with alcohol and drug use disorder (2017).

4. K.R.Ramya Sr. Lisa paul. Psychosocial problem of wives of alcoholic.volume-3. Asian Journal of Nursing Education of Research.(2013). .

5. Prof Dr.Madhavi. A Comparative study on selfesteem of adjustment among adolescents children of alcoholic and non-alcoholic father. Coimbatore. (2016). 